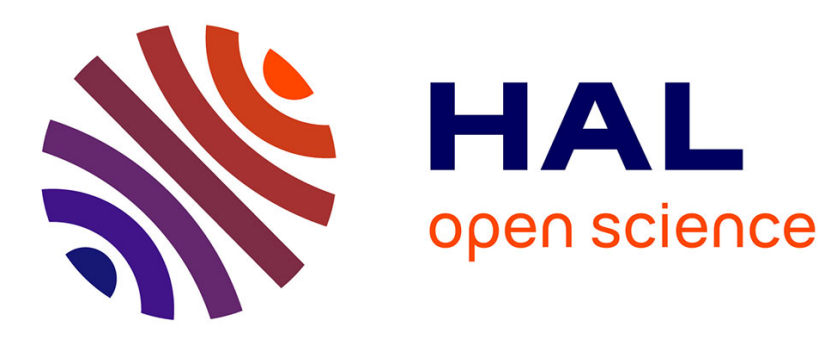

\title{
Distribution Grid Planning Enhancement Using Profiling Estimation Technic
}

Siyamak Sarabi, Arnaud Davigny, Vincent Courtecuisse, Léo Coutard, Benoit Robyns

\section{- To cite this version:}

Siyamak Sarabi, Arnaud Davigny, Vincent Courtecuisse, Léo Coutard, Benoit Robyns. Distribution Grid Planning Enhancement Using Profiling Estimation Technic. CIRED Workshop 2016, Jun 2016, Helsinki, Finland. hal-01392912

\section{HAL Id: hal-01392912 https://hal.science/hal-01392912}

Submitted on 5 Nov 2016

HAL is a multi-disciplinary open access archive for the deposit and dissemination of scientific research documents, whether they are published or not. The documents may come from teaching and research institutions in France or abroad, or from public or private research centers.
L'archive ouverte pluridisciplinaire HAL, est destinée au dépôt et à la diffusion de documents scientifiques de niveau recherche, publiés ou non, émanant des établissements d'enseignement et de recherche français ou étrangers, des laboratoires publics ou privés. 


\title{
Distribution Grid Planning Enhancement Using Profiling Estimation Technic
}

\author{
Siyamak Sarabi*, Arnaud Davigny*, Vincent Courtecuisse ${ }^{\dagger}$, Léo Coutard $^{\dagger}$, Benoit Robyns $^{*}$ \\ ${ }^{*}$ L2EP-HEI, France, siyamak.sarabi@hei.fr, ${ }^{\dagger}$ GEREDIS Deux-Sèvres, France
}

Keywords: Distribution grid, Profiling estimation, HV/MV substation, MV/LV substation, Artificial neural networks,

\begin{abstract}
In this study, the load profile estimation is done using the profiling technic, and its performance is enhanced using the real consumption values of the consumers. The results of estimation are evaluated using the measured data at the level of HV/MV (High Voltage/Low Voltage) substation and also MV feeders containing industrial and residential consumers and wind power productions. Based on the gap between actual measured data and estimated profiles, a correction factor is introduced that is applicable at the level of single MV/LV substations. These factors will be used for grid simulation and planning studies where the results will be more reliable compared to the previous estimation technics.
\end{abstract}

\section{Introduction}

Planning of power distribution system is one the main responsibilities of Distribution System Operators (DSO) which will provide them the appropriate decision making strategies related to the distribution grid's state and reinforcement necessities [1]. The growing nature of electricity demand enforces the DSO to have a perspective view on grid reinforcement capacity. This perspective should be in different temporal term from short term to long term perspective (typically a ten year investment plan is considered) [2]. Historically, distribution grids were sized to ensure the consumption peak, the massive integration of distributed generation requires today to take it into account in the design of the distribution grid [3].

The mastery of the short-term consumption (week/month) allows optimizing operations and driving patterns of grids (joules limit losses and minimize routing costs, operating plan in case of accident). In other side, the future smart grid contributions to the distribution grid need massive flow of information through the communication infrastructure. Advanced metering infrastructure are growing to prepare actual distribution grid for future smart grid [4]. The metering infrastructure is supposed to be available for each single consumer point. While currently, the actual measuring units provide only the consumed energy of the consumers but not the real power. Hence having a load profile of the single consumer is not possible.
Knowing that, the real power consumption of the network is necessary for planning and reinforcement studies, estimative technics provide possible solution to the problem prior to communication infrastructure development. As the actual reliable measurement of the distribution grid state is at the level of HV/MV substation (230-63 kV/20-15 kV), an estimation technic can calculate the actual load profile of the downstream consumers and evaluate its precision using measurement at HV/MV substation level.

In this paper, the aim is to reconstruct the load profile of the MV/LV substations using profiling technics and enhancement strategies presented in next sections. In section 2 , data preprocessing are explained which prepares the appropriate data for the algorithm. After that, in section 3, the load profile at the head of MV feeder will be reconstructed then in section 4 the profiling technic is explained and applied in one feeder as case study.

\section{Data pre-processing}

In order to do the profiling calculations the necessary data must be prepared. Each type of data comes from the different data base. As manager of the distribution grid of Deux-Sèvres department, GEREDIS, has access to certain information at different points of the electricity grid. The structure of data base preparation are depicted in Fig.1.

To calculate the profiles the following values are required;

1. The annual consumption of each client from billing server.

2. Information of the contract and price of each customer on billing server.

3. The reference of each customer to find out the position of that client on the network (available on billing server).

4. The distribution substation, the MV feeder and HV/MV substation position of each client on Geographic Information System (GIS) server.

\section{MV feeder profile correction}

The substation presented in Fig. 2 is located at the border between TSO (Transmission System Operator) and DSO. Each substation normally contains $3 \mathrm{HV} / \mathrm{MV}$ transformers. The 


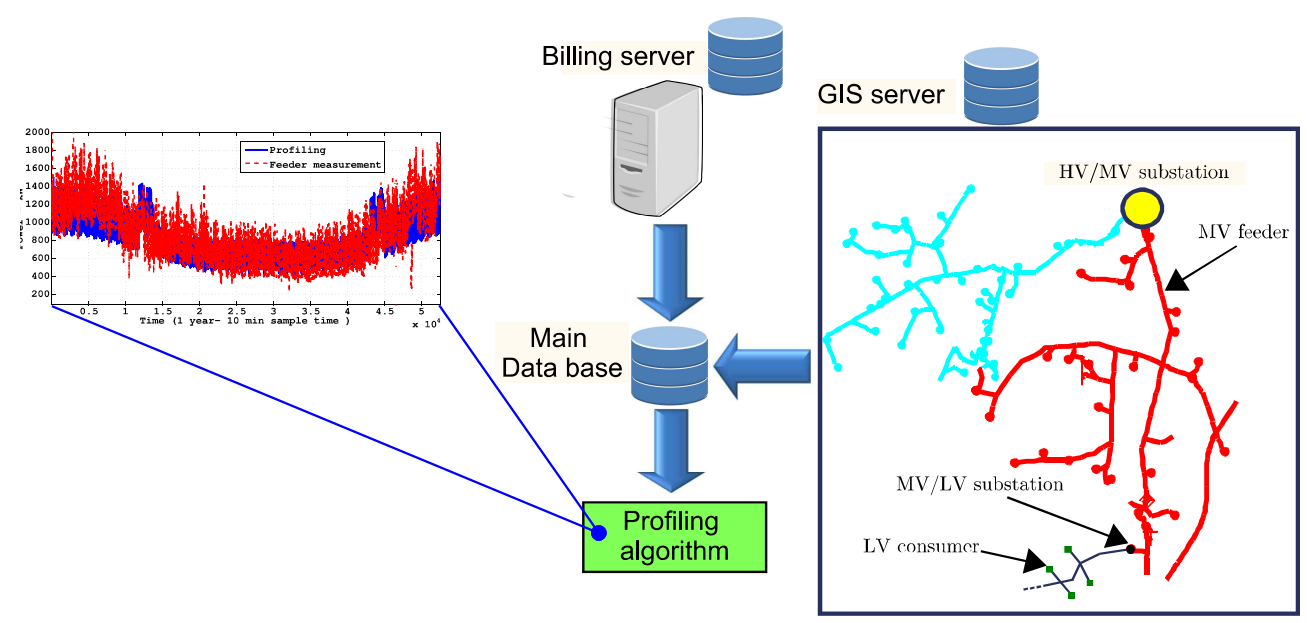

Fig. 1: The structure of profiling estimation using GIS and billing servers' data bases.

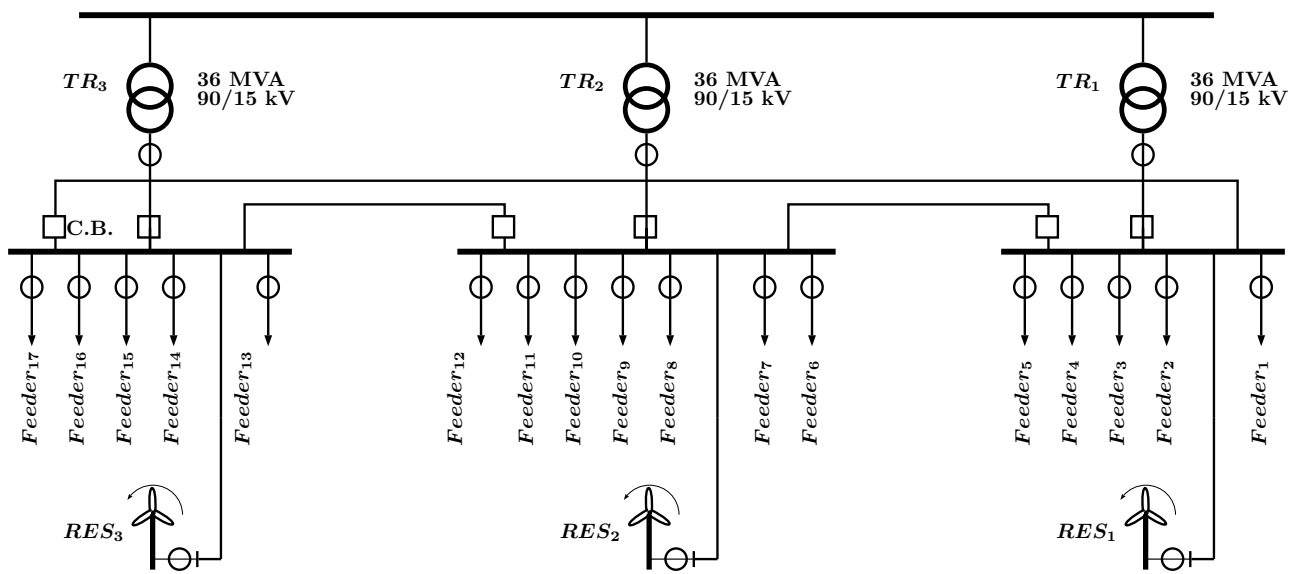

Fig. 2: The HV/MV substation diagram with its MV feeders.

measurement of power at 10 minutes sample time is provided at the level of each transformer. These measurements are used for billing the energy transmission cost and so they are accurate and available continuously. Second level of measurement are located at the head of each MV feeder containing both consumption and production feeders. The measurements at this level are not reliable and there are a lot of communications lost. Hence, the first step is to find the complete data using the values of measurement of first level at transformer. This step is done using an Artificial Neural Network (Fig. 3). The results are brought in Fig. 4. The algorithm tries to learn from available data to estimated the missed data. As the inputs of ANN, energy price $\left(E_{\text {price }}\right)$, day type vectors (Day type Day $_{\text {type }}^{1-365}$, Day type $1-144$ Day type $)$ and temperature are used. Afterwards, using the corrected profile of the feeder, the profiling estimation will be examined. The correction procedure should follow the rules described below.

$$
\begin{gathered}
P_{T R 1}=P_{\text {feeder } 1}+\ldots+P_{\text {feeder } 5}-P_{R E S 1} \\
P_{T R 2}=P_{\text {feeder } 6}+\ldots+P_{\text {feeder } 12}-P_{R E S 2}
\end{gathered}
$$

$$
P_{T R 3}=P_{\text {feeder } 13}+\ldots+P_{\text {feeder } 17}-P_{R E S 3}
$$

Where $P_{T R x}$ is the power of transformer $T R_{x}$ which includes the summation of all consumer feeders $\left(P_{\text {feeders }}\right)$ and substraction of local production in $P_{R E S x}$.

\section{Enhanced Profiling technic}

Profiling is a statistical technic for modeling of consumption (or production) applied to a group of clients [5]. As lead manager of the distribution network, ERDF, is responsible for establishing and making available the national profiles of market players' consumption and production contract applied to replenish the half-hourly energy flows through responsible balance.

The methodology of profiling based on annual consumption values of each customer for the various sub profiles in each profile type is explained on forms of below equations. 


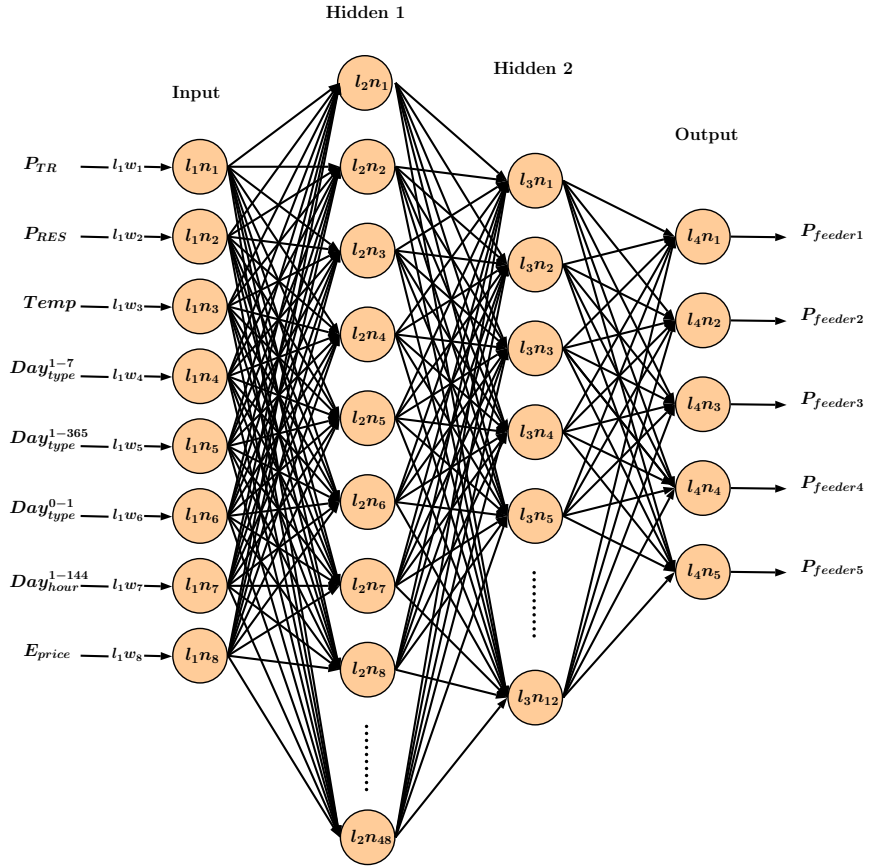

Fig. 3: ANN model for missed data estimation at MV feeder.

$$
\begin{gathered}
P_{\text {profiling }}^{j}=\sum_{i=1}^{k}\left(\frac{H_{P i}}{2 H_{y}} \times E_{y}^{j}\right) \times P_{p f}^{j}(t) \\
P_{\text {profiling }}^{j}=\left(\frac{E_{y}^{j}}{2 H_{y}} \times P_{p f}^{j}(t)\right)\left(H_{P 1}+H_{P 2}+\cdots+H_{P k}\right) \\
\left(H_{P 1}+H_{P 2}+\cdots+H_{P k}\right)=H_{y} \\
P_{\text {profiling }}^{j}=\left(\frac{E_{y}^{j}}{H_{y}} \times P_{p f}^{j}(t)\right)
\end{gathered}
$$

Where $P_{\text {profiling }}^{j}$ is the annual load profile of the consumer $j$ containing the $k$ typical consumption periods. This consumer has a typical consumption profile defined by $P_{p f}^{j}(t)$, with its annual consumption of $E_{y}^{j}$ in $\mathrm{kWh}$.

Afterwards, the sum of profiles of all consumers under the MV/LV substation $z$ will give the profile of this substation. For MV feeder $w$, the profile is given by (9).

$$
\begin{aligned}
& P_{\text {profiling }}^{z}=\sum_{j=1}^{J} P_{\text {profiling }}^{j} \\
& P_{\text {profiling }}^{w}=\sum_{z=1}^{Z} P_{\text {profiling }}^{z}
\end{aligned}
$$

The estimated profile of the MV feeder $w$ will be compared with the corrected measured data of the feeder calculated in previous section. The results are shown in Fig. 5. The difference is presented as an error factor as follows:

$$
\operatorname{Error}^{w}(t)=P_{\text {measured }}^{w}(t)-P_{\text {profiling }}^{w}(t)
$$
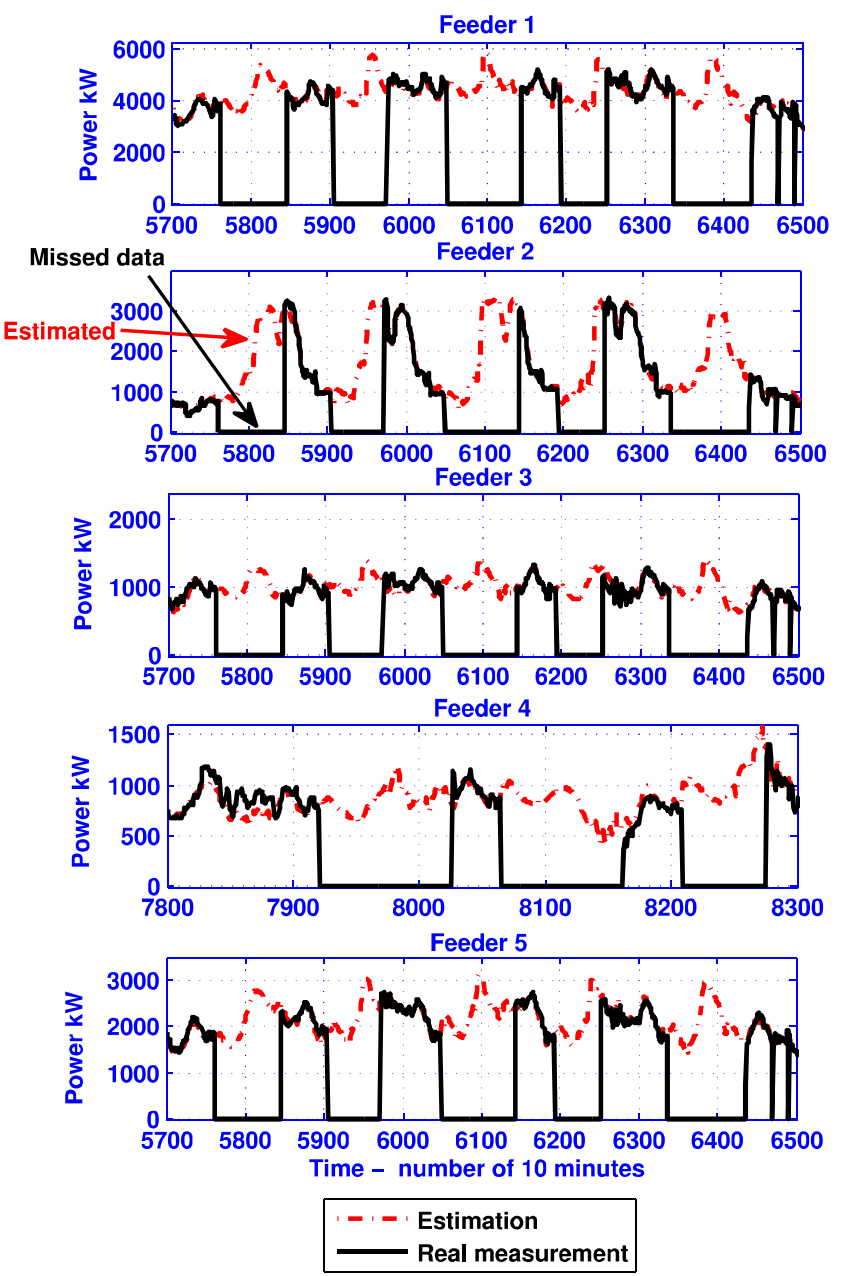

Fig. 4: MV feeders' profile correction for transformer $1, T R_{1}$.

Using the error profile, the modified profile of MV/LV subsation $z$ is calculated in (11).

$P_{\text {Mprofiling }}^{z}(t)=\left[\operatorname{Error}^{w}(t) \times \frac{P_{\text {profiling }}^{z}(t)}{P_{\text {profiling }}^{w}(t)}\right]+P_{\text {profiling }}^{z}(t)$

In fact, the difference between measured profile and estimated profile at the level of MV feeder is propagated in the profiles of the MV/LV substations under this feeder as shown in Fig. 6. In other word, the estimated profiles' accuracy is enhanced using measured data at MV feeder level. This algorithm is applied on each single MV/LV substation to calculate its profile. An illustrative example of some substations' profiles are given in Fig. 7. These profiles are now more reliable than only estimation technics as their accuracy are enhanced using real measured data at upper levels.

\section{Conclusion}

In this paper, an estimation technic for load profile reconstruction was presented. As there is no communication infrastructure at the level of MV/LV substations, the profile of these sub- 

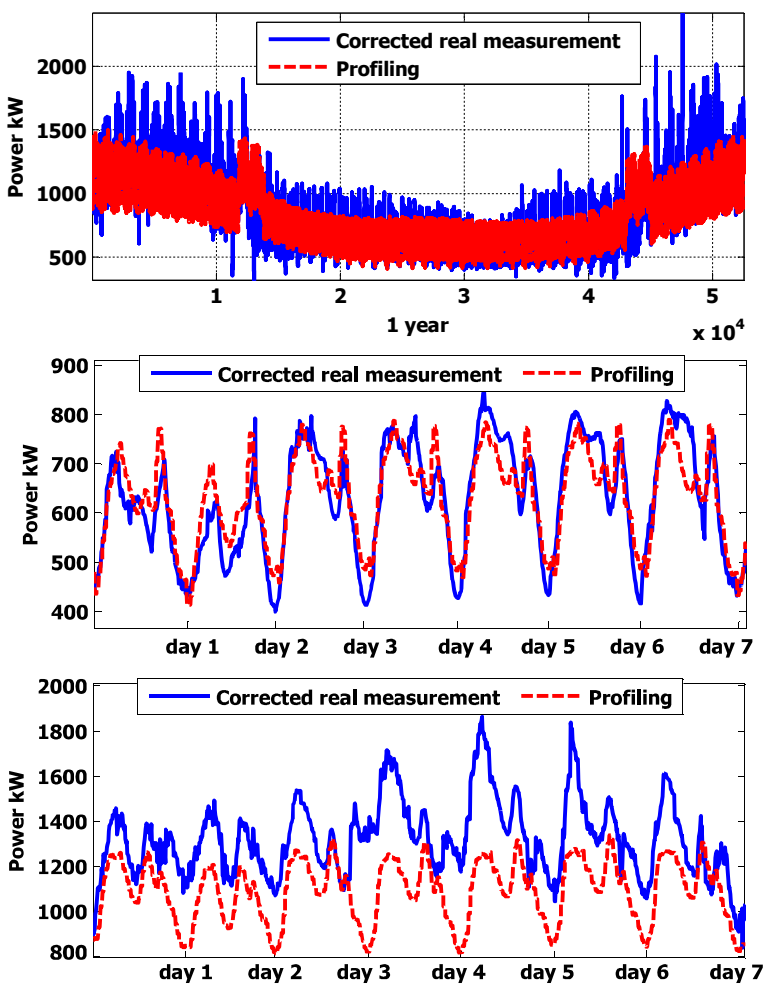

Fig. 5: Comparison of profiling output with corrected real measurement profile of MV feeder. Upper subplot: one year profile for feeder 13, Middle subplot: one week of summer, Lower subplot: one week of winter.
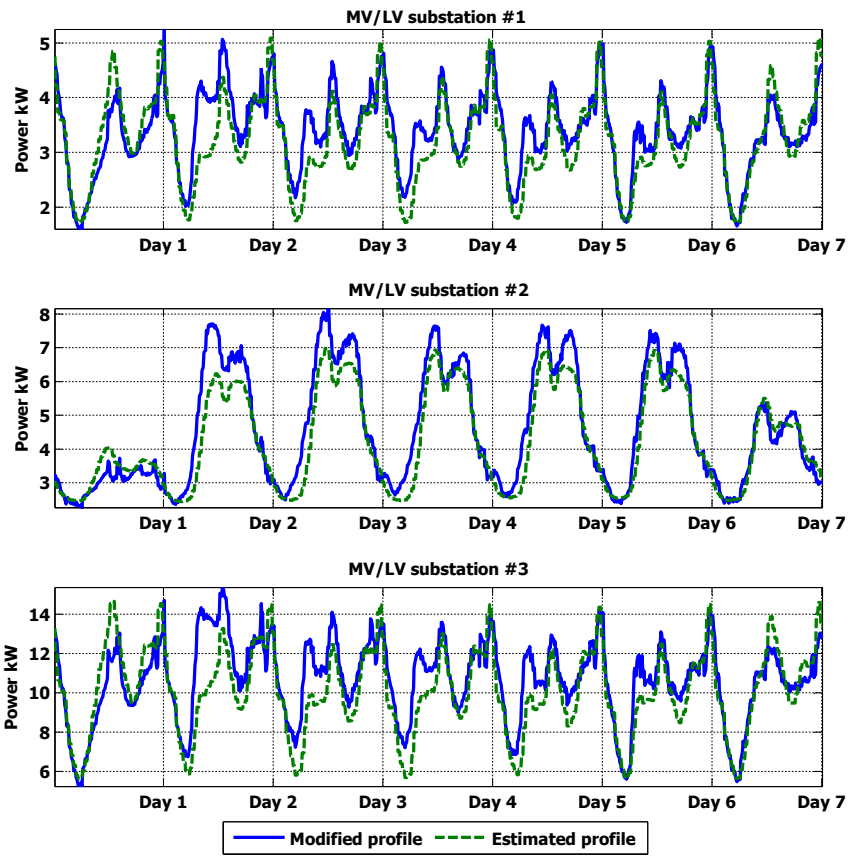

Fig. 6: Comparison of profiling output with modified profile of $3 \mathrm{MV} / \mathrm{LV}$ substations.

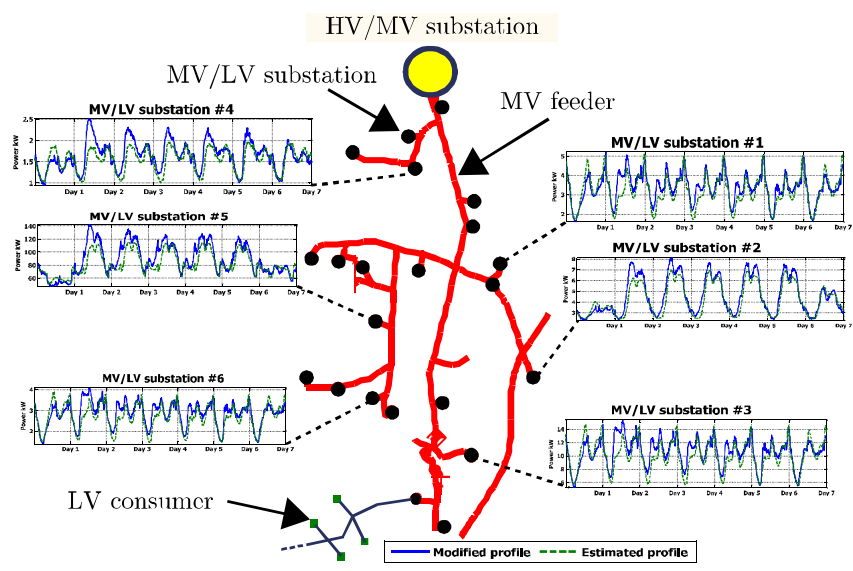

Fig. 7: Illustration of some profiles at MV/LV substation level.

stations are valuable in term of distribution grid planning and dimensioning. Load profiles of MV/LV substations were estimated using profiling estimation technics. In addition, their accuracy were enhanced using real measurement data firstly at HV/MV substation level then at MV feeder level. The reconstructed MV/LV substations' profiles can be used for distribution grid planning and simulation purposes. The condition of each substation under its enhanced estimated profiles can be evaluated from distribution grid operator point of view.

\section{References}

[1] S. Barsali, G. Celli, M. Ceraolo, R. Giglioli, P. Pelacchi, F. Pilo, Operating and planning issues of distribution grids containing diffuse generation, in: Electricity Distribution, 2001. Part 1: Contributions. CIRED. 16th International Conference and Exhibition on (IEE Conf. Publ No. 482), Vol. 4, 2001, pp. 5 pp. vol.4-. doi:10.1049/cp:20010846.

[2] B. Robyns, B. François, A. Davigny, J. Sprooten, A. Henneton, Electricity production from renewables energies, Wiley, 2012.

[3] S. Sarabi, A. Davigny, Y. Riffonneau, V. Courtecuisse, B. ROBYNS, Contribution and Impacts of Grid Integrated Electric Vehicles to the Distribution Networks and Railway Station Parking Lots, in: 23rd International Conference and Exhibition on Electricity Distribution (CIRED 2015), CIRED 2015, Lyon, France, 2015, pp. $1-5$.

[4] A. Bouallaga, R. Kadri, V. Albinet, A. Davigny, F. Colas, V. Courtecuisse, A. Merdassi, X. Guillaud, B. Robyns, Advanced metering infrastructure for real-time coordination of renewable energy and electric vehicles charging in distribution grid, in: CIRED Workshop, 2014.

[5] Profiles and profiling, ERDF, http://www.erdf. fr/profiles-and-profiling (2014). 